\title{
Necropsy study on glomerulonephritis in the elderly
}

\author{
P. R. POTVliege, G. DE ROY, AND F. DUPUIS \\ From the Department of Pathological Anatomy and the Department of Internal Medicine, University \\ Hospital Brugmann, Brussels, Belgium
}

SYNOPSIS The necropsy reports and clinical observations of 44 cases of glomerulonephritis occurring in patients over 55 years old were reviewed. Two-thirds of the patients died from a rapidly progressive renal disease with focal necrotizing and fibrosing glomerular lesions; half of these exhibited a granulomatous splenic trabeculitis; an associated vasculitis was found in only a minority of these cases. Another important group consisted of cases of acute diffuse glomerulonephritis which, as a rule, occurred in association with a major infection. There were only four cases of chronic sclerosing glomerulonephritis.

It is generally held that glomerulonephritis is rare in the elderly. In the literature, however, there is a paucity of pertinent and recent data on this subject, and it therefore seemed worthwhile to make a retrospective study of the 44 case reports of glomerulonephritis occurring in the elderly which were housed in the necropsy files of a general hospital. We found that cases of chronic sclerosing glomerulonephritis were rare indeed. Almost two-thirds of our patients had died from a rapidly progressive renal disease with focal necrotizing and fibrosing lesions as the characteristic glomerular change: half of these cases exhibited a peculiar granulomatous splenic trabeculitis; an associated disseminated vasculitis was found in a minority of patients. Another important group was formed by cases of acute diffuse glomerulonephritis which generally occurred in association with a severe infection.

\section{Material and Methods}

The cases which form the subject of this work were all subjected to necropsy in the same department of pathology during a 17-year period, from 1956 to 1972. Their primary selection was based on the following criteria:

(a) the subject was at least 55 years old, and

(b) glomerulonephritis had been diagnosed by the pathologist in charge.

After the relevant histological slides had been checked, 44 cases were retained. In view of the advanced age of most patients and the severity of

Received for publication 5 May 1975. their illness, a kidney biopsy was taken in only two cases. The morphological investigation was therefore restricted to the study of paraffin slides stained by conventional methods. The necessary controls were drawn from the same necropsy material, care being taken to collect them randomly in comparable age categories. The clinical records were independently studied by one of us. Statistically significant correlations were assessed by Fisher's test (Hill, 1971).

\section{Results}

The ages of our 44 patients ranged from 55 to 88 with a median of 67 years. There were 12 women and 32 men; this sex ratio is significantly different from the proportions registered in 500 controls, namely, 240 women and 260 men.

According to the histopathology of the glomerular lesions, the cases were distributed into three groups which will be presented separately. They correspond to: (1) rapidly progressive glomerulonephritis; (2) diffuse acute glomerulonephritis; and (3) diffuse glomerulonephritis of miscellaneous, nonacute types (table I).

Histological examination of the spleen revealed an unsuspected frequency of granulomatous inflammatory changes of the splenic trabeculae. They will be described under a separate heading (table II).

RAPIDLY PROGRESSIVE GLOMERULONEPHRITIS This group comprises eight women and 20 men whose ages ranged from 55 to 88 with a median of $64 \frac{1}{2}$ years.

The characteristic renal lesion may be defined as a 


\begin{tabular}{|c|c|c|c|}
\hline & \multicolumn{3}{|l|}{ Glomerulonephritis } \\
\hline & Rapidly Progressive & Acute & Other \\
\hline $\begin{array}{l}\text { Number of cases } \\
\text { Number of males } \\
\text { Median age }(\mathrm{yr})\end{array}$ & $\begin{array}{l}28 \\
20 \\
641 / 2\end{array}$ & $\begin{array}{r}8 \\
5 \\
73\end{array}$ & $\begin{array}{r}8 \\
7 \\
67\end{array}$ \\
\hline $\begin{array}{l}\text { Duration of disease: } \\
\text { up to } 3 \text { months } \\
3 \text { to } 6 \text { months } \\
\text { more than } 6 \text { months } \\
\text { unknown }\end{array}$ & $\begin{array}{r}20 \\
4 \\
2 \\
2\end{array}$ & $\begin{array}{l}6 \\
1 \\
0 \\
1\end{array}$ & $\begin{array}{l}3 \\
1 \\
3 \\
1\end{array}$ \\
\hline $\begin{array}{l}\text { Extrarenal pathology: } \\
\text { Major infection } \\
\text { Bacterial endocarditis } \\
\text { Disseminated vasculitis } \\
\text { Malignant tumour } \\
\text { Fibrinous pericarditis } \\
\text { Splenic trabeculitis }\end{array}$ & $\begin{array}{l}6 \\
1 \\
6 \\
3 \\
11 \\
11 / 20\end{array}$ & $\begin{array}{l}5 \\
2 \\
0 \\
2 \\
0 \\
1 / 7\end{array}$ & $\begin{array}{l}0 \\
0 \\
2 \\
1 \\
3 \\
1 / 8\end{array}$ \\
\hline
\end{tabular}

Table I Main findings in 44 cases of glomerulonephritis occurring in patients over 55 years old

\begin{tabular}{|c|c|c|c|c|c|c|c|c|c|}
\hline \multirow[t]{2}{*}{ Sex } & \multirow[t]{2}{*}{ Age } & \multirow[t]{2}{*}{ Type of $G N$} & \multicolumn{2}{|c|}{ Splenic Lesion } & \multicolumn{3}{|c|}{ Weight $(g)$} & \multirow{2}{*}{$\begin{array}{l}\text { Fibrinous } \\
\text { Pericarditis }\end{array}$} & \multirow[t]{2}{*}{ Extrarenal Pathology } \\
\hline & & & Trabeculitis & Vasculitis & Spleen & Kidneys & Heart & & \\
\hline $\mathbf{F}$ & 55 & Focal & + & 0 & 470 & 270 & 430 & 0 & \\
\hline $\mathbf{M}$ & 58 & Focal & + & $\mathbf{0}$ & 170 & 200 & 450 & Adh. & Rheumatoid arthritis, silicosis \\
\hline $\mathbf{M}$ & 59 & Focal & + & $\mathbf{0}$ & 220 & 350 & 400 & + & \\
\hline $\mathbf{M}$ & 60 & Focal & + & $\mathbf{0}$ & 120 & $?$ & 400 & 0 & \\
\hline $\mathbf{M}$ & 61 & Focal & + & + & 180 & 450 & 450 & + & \\
\hline $\mathbf{M}$ & 63 & Focal & ++ & 0 & 150 & 370 & $?$ & + & Bacterial endocarditis, PAN \\
\hline $\mathbf{M}$ & 64 & Focal & ++ & $\mathbf{0}$ & 120 & 550 & 500 & + & \\
\hline $\mathbf{M}$ & 64 & Focal & + & ++ & 170 & 450 & 450 & 0 & PAN \\
\hline $\mathbf{M}$ & 68 & Focal & ++ & + & 150 & 410 & 500 & 0 & Lung aspergillosis \\
\hline $\mathbf{M}$ & 74 & Focal & ++ & ++ & 130 & 380 & 370 & + & PAN \\
\hline $\mathbf{M}$ & 81 & Focal & + & ++ & 90 & 250 & 450 & + & Allergic vasculitis \\
\hline $\mathbf{M}$ & 76 & Acute & + & + & 280 & 360 & 500 & $\mathbf{0}$ & $\begin{array}{l}\text { Bacterial endocarditis, carcinoma } \\
\text { colon }\end{array}$ \\
\hline $\mathbf{M}$ & 78 & Chronic & + & 0 & 170 & 430 & 440 & 0 & \\
\hline
\end{tabular}

Table II Splenic trabeculitis in 44 cases of glomerulonephritis affecting patients over 55 years old

GN = glomerulonephritis; PAN = polyarteritis nodosa.

segmental necrotizing and fibrosing glomerulitis. Even in those frequent cases where the lesions had become extensive, considerable variation was observed in the appearance of individual glomeruli, and such polymorphism was taken to indicate that the glomerulopathy was of an essentially focal nature (fig 1). Fibrinoid changes in the tufts were accompanied by varying degrees of leucocytic exudation and of intracapillary as well as epithelial cell proliferation (fig 2). The latter process sometimes led to the formation of large epithelial crescents. In some cases there was also an intense periglomerulitis which, added to segmental destruction of Bowman's capsule, disorganization of the tuft, and epithelial proliferation, transformed the glomerulus into a granulomatous nodule within which giant cells were occasionally seen (fig 3 ). Sclerosis clearly resulted from scarring of the tuft lesions and organization of the cell crescents. In individual glomeruli, local scars were sometimes observed side by side with still active necrotizing foci. Fibrinoid necrosis was the predominant glomerular change in 10 cases; in 13 others sclerosis dominated, while in the remaining five cases both types of change were equally represented. The rapidly fatal evolution of the disease demonstrated that the sclerosis was an early reaction which could develop in a few weeks.

Although focal glomerulitis was the outstanding change in this type of glomerulonephr itis, conspicuous inflammatory changes were regularly observed in the renal interstitium. There was diffuse proliferation of the connective tissue, leucocytic infiltration, sometimes with many eosinophils, and occasionally disseminated histiocytic granulomas with sparse giantcell reactions. In four cases, extensive papillary necrosis had occurred.

Extrarenal lesions were variable. A more or less disseminated vasculitis was found in six cases; in 


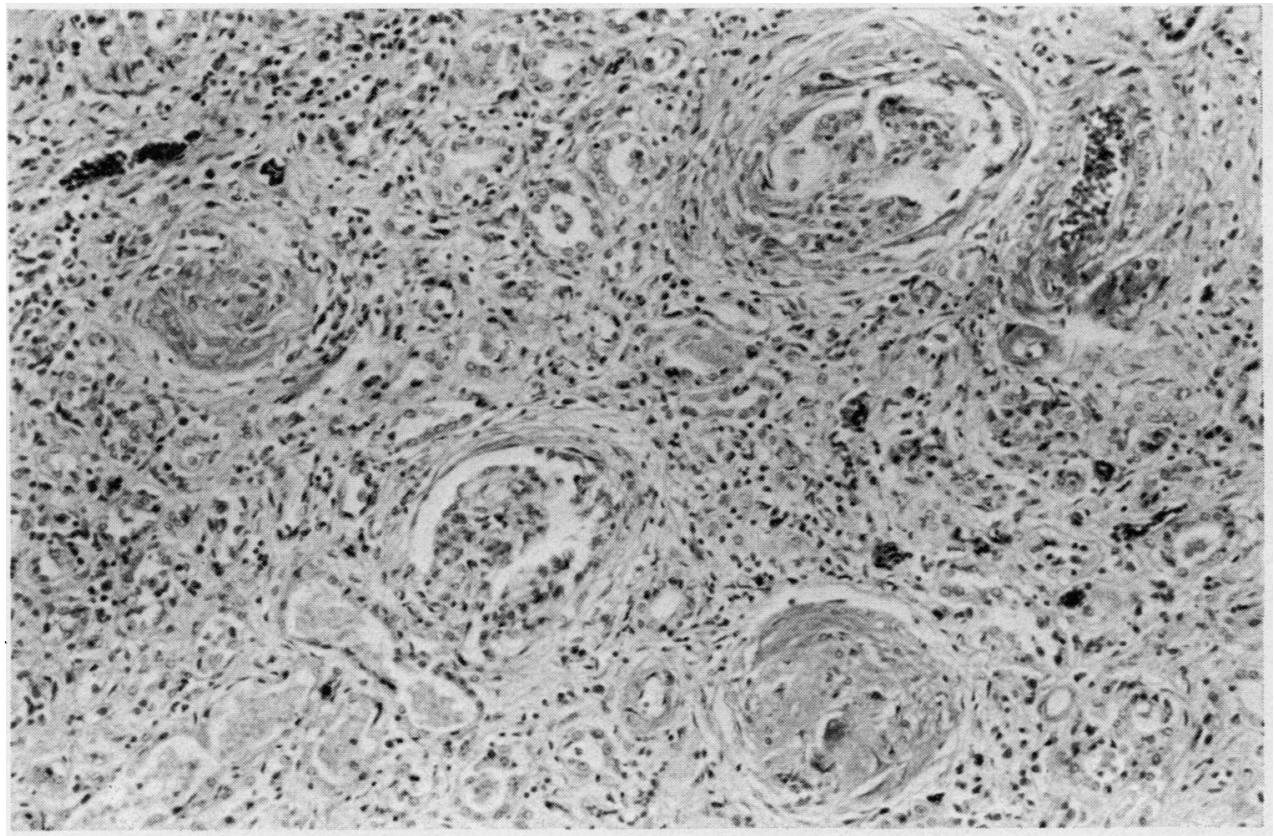

Fig 1 Focal rapidly progressive glomerulonephritis: four glomeruli are shown at different stages of scarring and exhibiting still identifiable remnants of cellular crescents; the interstitium is diffusely fibrosed. Male aged 67 years died in anuria after a two-month illness; positive serological tests for syphilis; no vasculitis and no trabeculitis. (Case 71.251-Masson's trichrome $\times 70$ ).

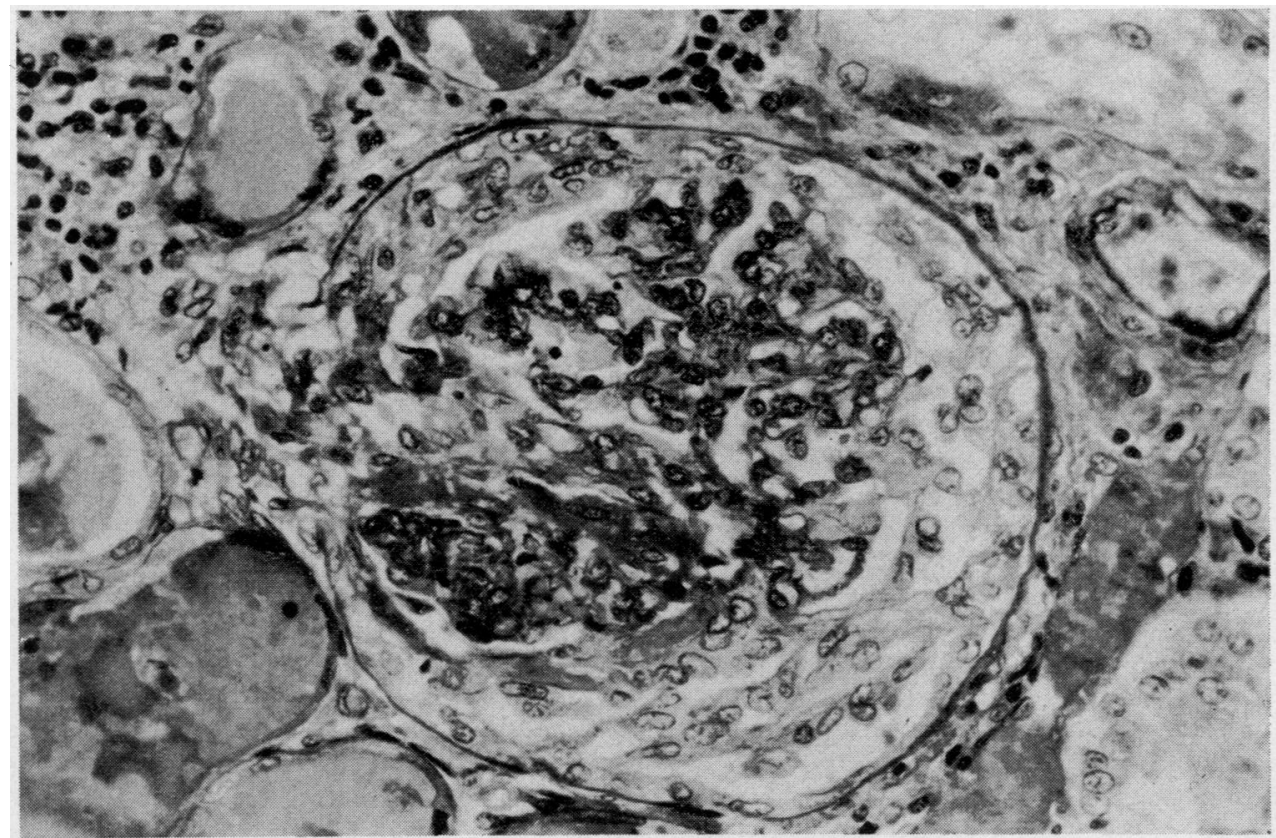

Fig 2 Focal rapidly progressive glomerulonephritis: glomerulus showing intracapillary and extracapillary proliferations with fibrinoid changes in the tuft. Female aged 55 years died in anuria after a three-month illness. At necropsy renal papillary necrosis, fibrinous pericarditis, no vasculitis, and no trabeculitis. (Case 58.376-Masson's trichrome $\times 180$ ). 


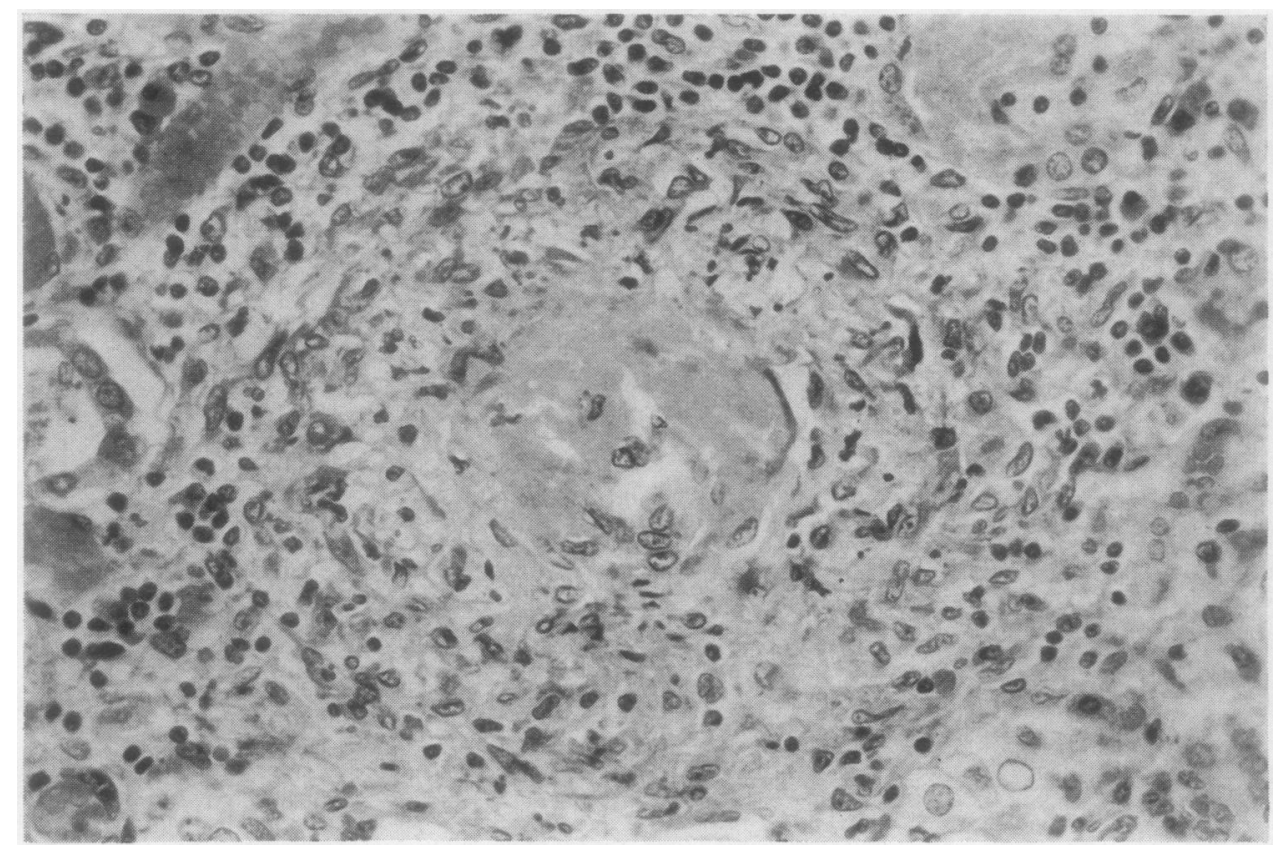

Fig 3 Same case as in figure 2. Complete destruction of a glomerulus by a granulomatous inflammatory reaction. (Masson's trichrome $\times 180$ ).

three of them it corresponded to typical polyarteritis nodosa and in one to rheumatoid purpura; in the two remaining cases, inconspicuous acute lesions were found, involving only a few small vessels in the spleen and kidneys. A major infection was present in six patients and had a septicaemic character in three of them. The histology of the spleen was studied in 20 cases; trabeculitis, of the type to be described later, was found in 11 of them, including the six patients suffering from disseminated vasculitis. A fibrinous pericarditis was found in 11 patients.

From the clinical point of view the majority of cases presented as a renal disease of unknown origin. The evolution was marked by the insidious onset of a renal insufficiency which, when it was declared, led rapidly to death from uraemia in a period which rarely exceeded four months. A nephrotic syndrome was observed in only one patient and was rapidly followed by the development of uraemia. Arterial hypertension was never a major problem. Haematuria was frequent. In those cases where a disseminated vasculitis was detected at necropsy, it had not been suspected during life.

DIFFUSE ACUTE GLOMERULONEPHRITIS

This group is made up of three women and five men aged 55 to 80 with a median of 73 years. The distri- bution according to sex is not significantly different from that of the preceding group.

In seven cases, the glomerulonephritis was of the exudative type, the glomerular tufts being diffusely infiltrated by a large number of polymorphonuclear leucocytes (fig 4). In two of these cases the glomeruli also showed conspicuous capillary thrombosis. In one patient suffering from a lung abscess the glomerulonepht itis was of the proliferative type. Other renal changes consisted of cholesterol embolization in one woman suffering from syphilitic aneurysm of the thoracic aorta.

The extrarenal pathology comprised five major infections, two of them being of a septicaemic nature and two malignant tumours. One man died with an allergic eruption which had appeared in the end stage of the disease. No fibrinous pericarditis or disseminated vasculitis was encountered at necropsy. Splenic trabeculitis was found in one of the seven cases where the spleen was examined histologically.

The clinical picture was dominated in most cases by the infectious or neoplastic process so that the early stage of the disease was regularly missed. It was estimated that the total duration of the nephropathy could have varied from one week up to six months with an average of some $2 \frac{1}{2}$ months. A severe renal insufficiency was noted in seven patients and was the cause of death in six of them. 


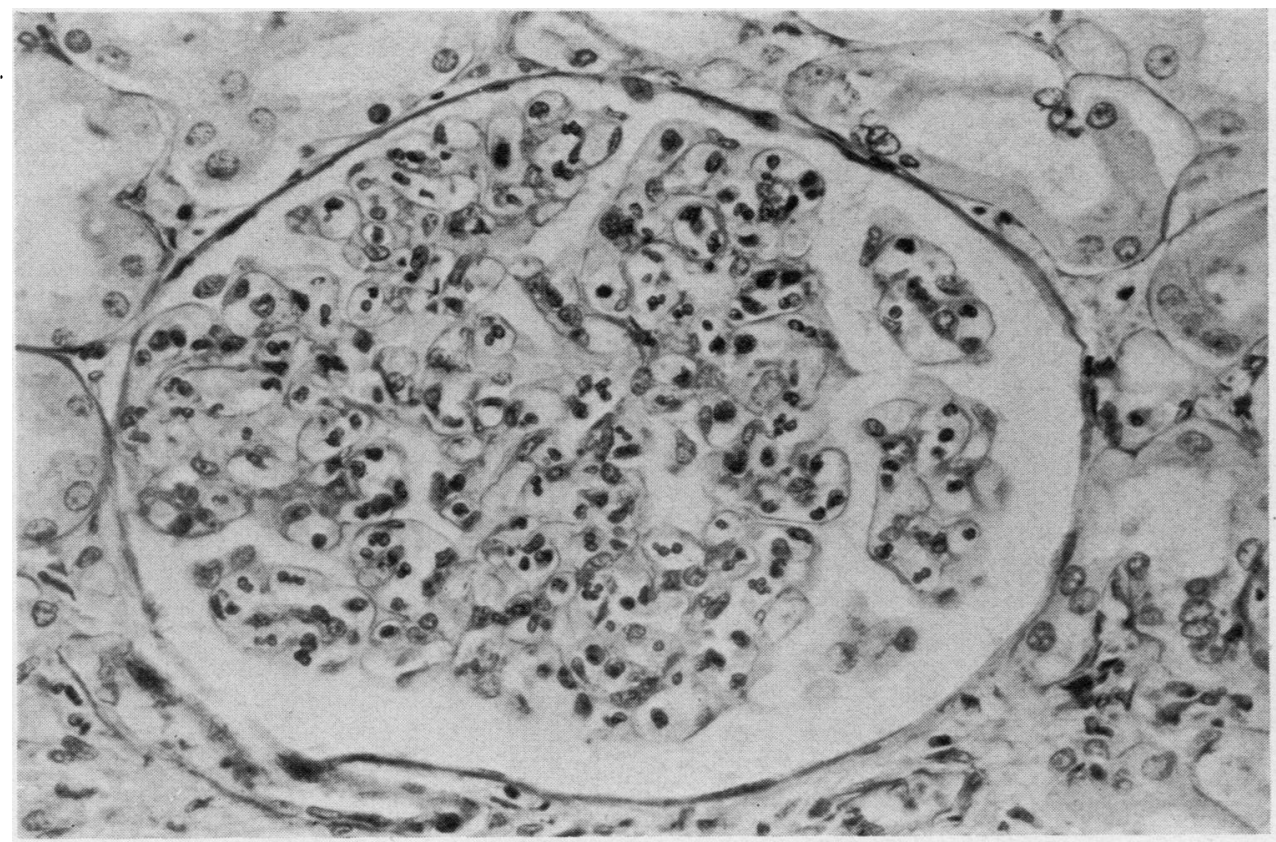

Fig 4 Acute glomerulonephritis of the exudative type. Female aged 70 years died in renal failure after a six-month illness; Antistreptolysin $O$ titre $500 \mathrm{U}$; syphilitic aneurysm of the aorta with cholesterol embolization in the kidney. (Case 63.261-PAS × 180).

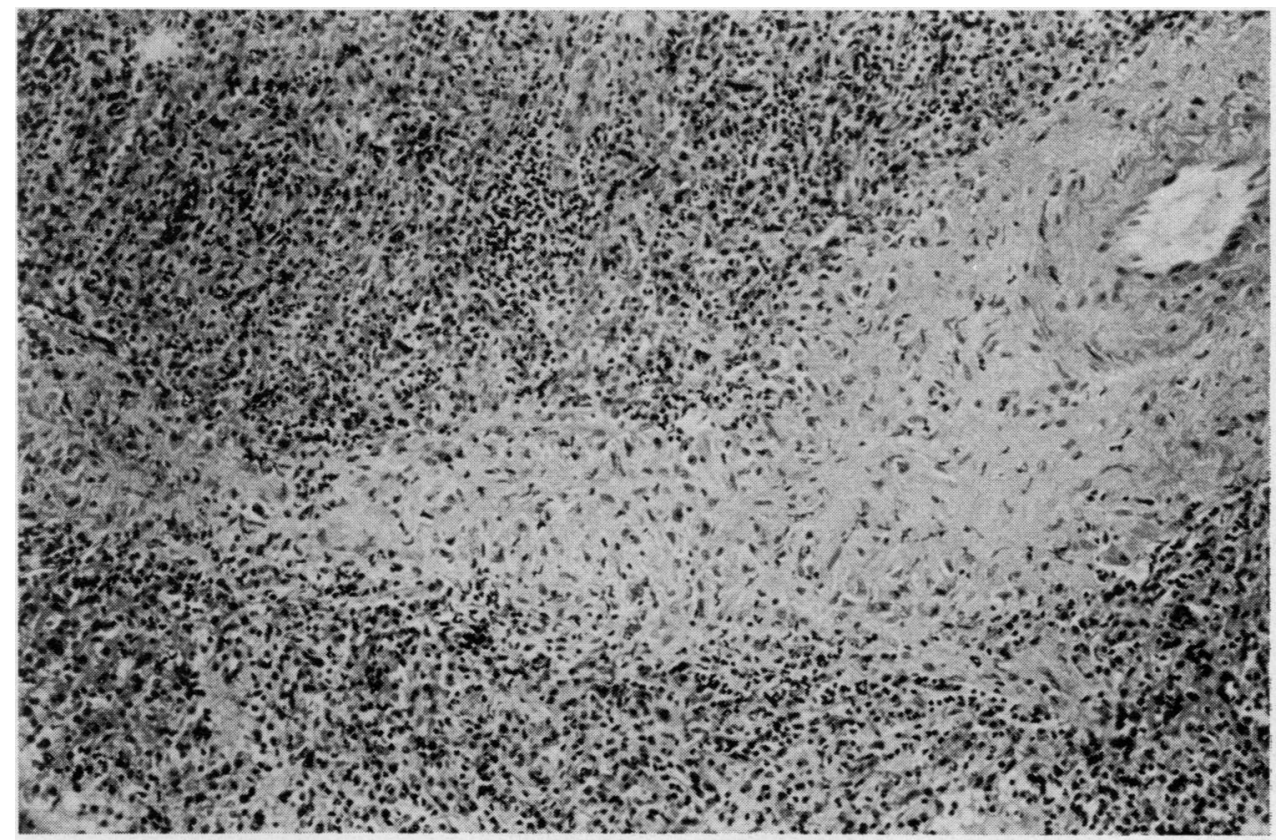

Fig 5 Granulomatous trabeculitis discovered in a needle biopsy of the spleen. Male aged 59 years died of uraemia after a two-month illness. At necropsy six weeks after the biopsy: focal rapidly progressive glomerulonephritis, fibrinous pericarditis, and granulomatous trabeculitis of the spleen; no vasculitis. (Case 61.327-Haematoxylin and eosin $\times 70$ ). 


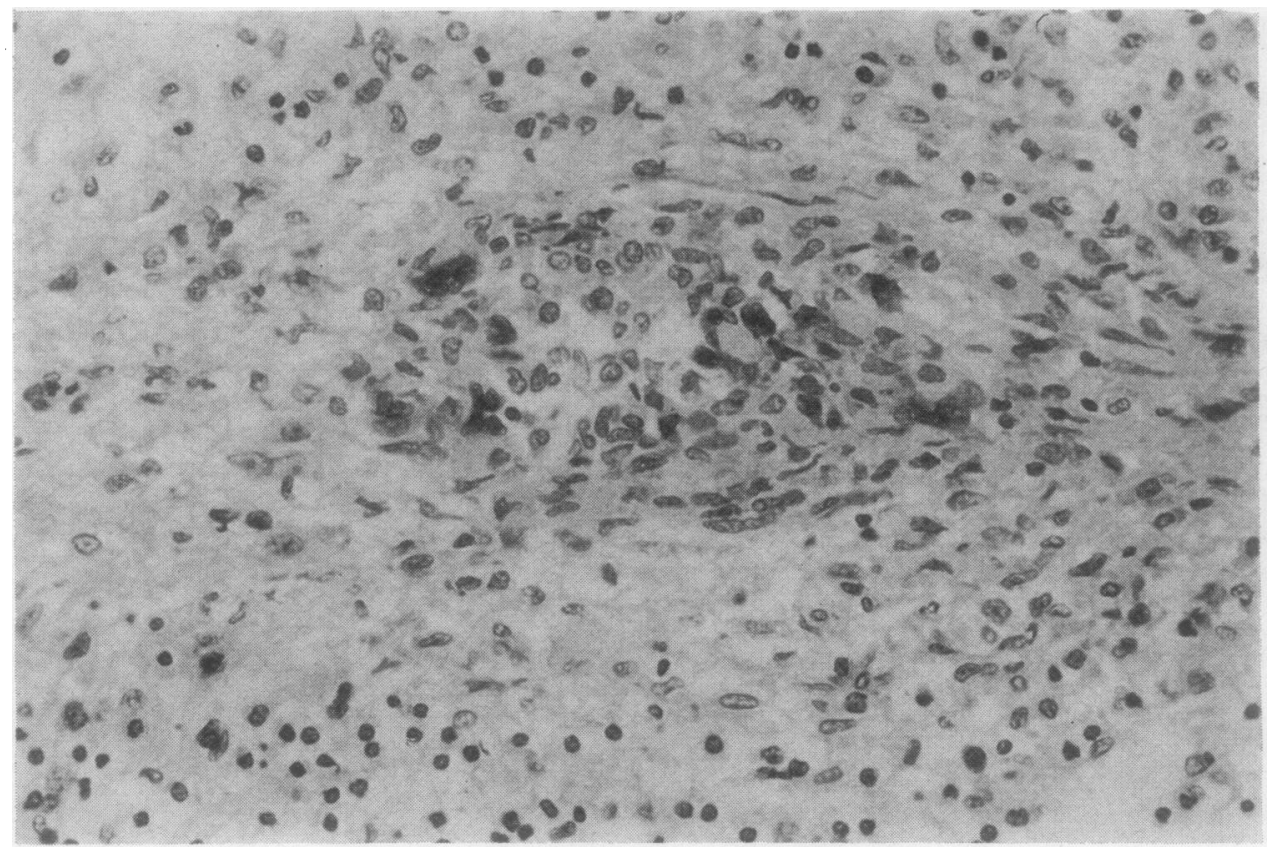

Fig 6 Granulomatous nodule with a slight giant-cell reaction in a splenic trabecula. Male aged 81 years died in uraemia after a one-month illness marked by purpura and oedema. At necropsy focal rapidly progressive glomerulonephritis, disseminated allergic vasculitis, fibrinous pericarditis, and splenic trabeculitis (Case 68.443-H and $E \times 180$ ).

Three patients had haematuria and one of them also had haemoptysis. Arterial hypertension was never conspicuous. A recent streptococcal infection was demonstrated in one case by the raised serum antistreptolysin titre; in two other cases, bacteriological investigation brought to light, respectively, Staphylococcus aureus and Listeria monocytogenes infections.

\section{DIFFUSE GLOMERULONEPHRITIS OF} MISCELLANEOUS NON-ACUTE TYPES

This group also comprised eight patients, one woman and seven men aged from 55 to 86 with a median of 67 years.

Four cases came under the heading of chronic sclerosing glomerulonephritis.

Three cases were considered to be examples of thrombotic glomerulopathy, as evidenced by the presence of thrombosed capillaries in glomerular tufts showing in addition slight proliferative changes, fibrillary deposits of basement membrane-Jike material, and a sprinkling of polymorphonuclear leucocytes. In two of these cases, disseminated vasculitic lesions were found at necropsy.

The last case was a membranous glomerulone- phritis associated with a bronchial epidermoid carcinoma.

A fibrinous pericarditis was observed in four cases. Splenic trabeculitis was encountered in one case in the absence of disseminated vasculitis.

\section{SPLENIC LESIONS}

The characteristic changes were seen mainly along the borders of the trabeculae, the edges of which appeared fi ayed and were dissociated by granulomatous foci extending for a short distance into the adjoining tissue (fig 5). The granulomas were composed of histiocytes, sometimes of epithelioid appearance, and were in certain cases infiltrated by polymorphonuclear leucocytes; giant cells were infrequent (fig 6). Necrotic changes, of either caseous or fibrinoid type, were absent. The central parts of the affected trabeculae were sometimes infiltrated by lymphocytes and plasma cells. The granulomatous trabeculitis was regularly associated with comparable lesions in the deep portion of the capsule where there were frequently fibrinoid changes and evidence of old haemorrhage.

A search was made for statistically significant correlations between trabeculitis and other lesions. 
There was a weak correlation with focal type of glomerulonephritis $(P<0.05)$ and with angiitis $(\mathrm{P}<0.02)$; there was no correlation with actively necrotizing processes in the glomeruli or with the occurrence of fibrinous pericarditis.

\section{Discussion}

The main facts to emerge from a retrospective postmortem study of 44 cases of glomerulonephritis occurring in adults over the age of 55 years were the following:

1 The proportion of males in this group was significantly higher than among the 500 controls taken randomly from the same necropsy material, $73 \%$ as compared with $52 \%$.

2 Almost two-thirds of our patients were victims of a locally necrotizing and fibrosing glomerulitis which led to total renal failure in a matter of weeks. A comparable clinical situation has been described by different authors under a variety of names, rapidly progressive glomerulonephritis probably being the most popular (Heptinstall, 1966). A relationship to streptococcal infection has been demonstrated or assumed in a number of cases, particularly when the lesions were diffuse and consisted mainly of extracapillary proliferation. On the other hand, glomerular foci of necrosis are more characteristically seen in association with systemic diseases such as polyarteritis nodosa, particularly in its micı oscopical form (Davson et ol, 1948), Wegener's granulomatosis, Goodpasture's syndrome, and rheumatoid purpura. Although it was this last type of damage which prevailed in our material, a relationship to angiitis was evidenced in only six of the 28 cases. Other factors which might conceivably have played a role in the aetiology were present in seven other cases and consisted of a major infection in four and a malignant tumour in three. In sum, the rapidly progressive glomerulonephritis which affected this group of patients appeared in the majority of them as a primary nephropathy of obscure aetiology.

3 Approximately half of the patients who died from the focal necrotizing and sclerosing form of glomerulonephritis exhibited in their spleen a granulomatous inflammation of the trabeculae. Trabeculitis is an uncommon lesion. We have seen it with a certain frequency in only three other groups of patients: $(a)$ in cases of acute leukaemia, where the trabeculitis probably represents infiltration by leukaemic cells; $(b)$ in bacterial endocarditis; and (c) in polyarteritis nodosa, almost exclusively in association with glomerulonephritis. This last observation has also been made by Symmers (1958), who stressed the necrotic character of the trabeculitis; it might be adduced as evidence in favour of the view that all patients with a focal necrotizing glomerulonephritis of obscure aetiology are in fact affected by the microscopical form of polyarteritis nodosa, with vascular lesions so scant that they may easily escape detection. This view is as difficult to prove as to disprove, and we feel that it is possible, as was suggested by Heptinstall (1966), that we have to do with a continuous spectrum of disease in which glomerular, vascular, and trabecular lesions may overlap.

4 Second in importance in our series was the group of patients suffering from acute diffuse glomerulonephritis. A relationship to major infections was evidenced in a significantly higher proportion of cases than in the preceding group. From the clinical point of view there was no major difference between this group and the preceding one, so that finally the great majority of our elderly patients presented with a particularly severe and rapidly evolving renal disease. By contrast, the last stage of a chronically evolving glomerulonephritis was seen in only a small minority of cases.

In the literature, the common opinion, voiced by Ellis (1942), Fishberg (1947), and McKeown (1965), is that glomerulonephritis is rare in the elderly patient. On the other hand, Nesson and Robbins (1960), who like us investigated necropsy material, found that mortality from glomerulonephritis was higher in the group of patients over 50 years old and that these were affected by the acute and subacute more often than by the chronic forms of glomerulonephritis. Other workers have directed their attention more specifically toward the occurrence of acute glomerulonephritis in the aged (Boswell and Eknoyan, 1968; Arieff et al, 1971) and this association gains in significance when reports dealing with particularly severe forms of glomerulonephritis in adults are considered since they regularly comprise a fair proportion of elderly patients (Brun et al, 1958; Bialestock and Tange, 1959; Berlyne and Baker, 1964; Lee et al, 1966; Bacani et al, 1968; Lewis et al, 1971; Sonsino et al, 1972). The same situation is to be found in reports of rapidly progressive renal disease complicating the microscopical form of polyarteritis nodosa (Wainwright and Davson, 1950; Harrison et al, 1964; Ladefoged et al, 1969) and Henoch-Schönlein's purpura (Ballard et al, 1970).

From this brief survey of the literature it appears that our observations are in close agreement with those reported by other authors. The frequency of glomerulonephritis in the aged, while not exactly known, is probably low. The cases which have attracted the most attention and are possibly the most frequent are those which pursue a rapidly progressive course; from the point of view of their aetiology, they clearly form a heterogeneous collection, 
systemic disease and infections accounting for only part of them. As regards their pathogenesis, it appears possible that the severe glomerular damage which occurs in such cases may be mediated by antiglomerular basement membrane antibodies, the presence of which in glomeruli, the serum or both was demonstrated by Lewis et al (1971) in six out of seven adult cases of rapidly progressive glomerulonephritis.

\section{References}

Arieff, A. I., Anderson, R. J., and Massry, S. G. (1971). Acute glomerulonephritis in the elderly. Geriatrics, 26(9), 74-84.

Bacani, R. A., Velasquez, F., Kanter, A., Pirani, C. L., and Pollak, V. E. (1968). Rapidly progressive (non streptococcal) glomerulonephritis. Ann. intern. Med., 69, 463-485.

Ballard, H. S., Eisinger, R. P., and Gallo, G. (1970). Renal manifestations of the Henoch-Schoenlein syndrome in adults. Amer. J. Med., 49, 328-335.

Berlyne, G. M. and Baker, S. B. de C. (1964). Acute anuric glomerulonephritis. Quart. J. Med., 33, 105-115.

Bialestock, D. and Tange, J. D. (1959) Acute necrotizing glomerulitis. Aust. Ann. Med., 8, 281-239.

Boswell, D. C. and Eknoyan, G. (1968). Acute glomerulonephritis in the aged. Geriatrics, 23(12), 73-80.

Brun, C., Gormsen, H., Hilden, T., Iversen, P., and Raaschou, F. (1958). Kidney biopsy in acute glomerulonephritis. Acta med. scand., 160, 155-163.

Davson, J., Ball, J., and Platt, R. (1948). The kidney in periarteritis nodosa. Quart. J. Med., 17, 175-202.
Ellis, A. (1942). Natural history of Bright's disease: clinical, histological and experimental observations. Lancet, 1, 1-7. Fishberg, A. M. (1947). Hypertension and Nephritis, 4th ed. Lea and Febiger, Philadelphia.

Harrison, C. V., Loughridge, L. W., and Milne, M. D. (1964). Acute oliguric renal failure in acute glomerulonephritis and polyarteritis nodosa. Quart.J. Med., 33, 39-55.

Heptinstall, R. H. (1966). Pathology of the Kidney. Churchill, London.

Hill, A. B. (1971). Principles of Medical Statistics. The Lancet, London.

Ladefoged, J., Nielsen, B., Raaschou, F., and Sørensen, A. W. S. (1969). Acute anuria due to polyarteritis nodosa. Amer. J. Med., 46, 827-831.

Lee, H. A., Stirling, G., and Sharpstone, P. (1966). Acute glomerulonephritis in middle-aged and elderly patients. Brit. med. J., 2, 1361-1363.

Lewis, E. J., Cavallo, T., Harrington, J. T., and Cotran, R. S. (1971). An immunopathologic study of rapidly progressive in glomerulonephritis in the adult. Hum. Path., 2, 185-208.

McKeown, F. (1965). Pathology of the Aged. Butterworths, London.

Nesson, H. R. and Robbins, S. L. (1960). Glomerulonephritis in older age groups. Arch. intern. Med., 105, 23-32.

Sonsino, E., Nabarra, B., Kazatchine, M., Hinglais, N., and Kreis, H. (1972). Les glomérulonéphrites prolifératives extracapillaires dites 'glomérulonéphrites malignes'. Actualités néphrol. Hôp. Necker, 119-161.

Symmers, W. St. C. (1958). The histological and cytological diagnosis of so-called collagen diseases. In Eight Colloquia on Clinical Pathology, edited by $\mathrm{M}$. Welch, P. Dustin, and J. Dagnelie. Presses Académiques Européennes, Brussels.

Wainwright, J. and Davson, J. (1950). The renal appearances of in the microscopic form of periarteritis nodosa. $J$. Pat Bact., 62, 189-196. 